\title{
Sistema Municipal de Unidades Protegidas da Cidade do Recife, Pernambuco, Brasil
}

\author{
Municipal System of Protected Units of Recife, Pernambuco, Brazil
}

Ubirajara Ferreira Paz

\section{Resumo}

A paisagem urbana é síntese do processo de urbanização e, sobretudo, da relação do homem com a natureza e de todos os formatos de intervenções no ambiente natural e no próprio ambiente construído. As áreas verdes são elementos imprescindíveis dessa paisagem urbana e componentes do patrimônio, construído ou natural. Têm essa importância não só pela notória contribuição no aspecto físico que marca a morfologia da cidade, mas também pelo que elas representam para a qualidade de vida. A cidade do Recife, caracterizada pela imensa rede de água, associada ao sistema de áreas verdes, revela-se como unidade ambiental entre águas e cobertura vegetal, o que a torna emblemática e singular. Este estudo objetiva analisar o Sistema de Unidades Protegidas do Recife no que ele estabelece sobre as áreas verdes públicas. No estudo, recorreu-se à compilação dos dispositivos estabelecidos no Plano Diretor do Recife que originaram a sua instituição, do agrupamento de suas diretrizes e componentes e da sua classificação, em função das tipologias das áreas verdes que o compõe. Como resultado, observou-se que, com a instituição do Sistema, além de ter surgido um importante instrumento de planejamento, verifica-se que o mesmo ampliou e diversificou as categorias de áreas.

Palavras chaves: Espaços públicos. Unidades de proteção da natureza. Instrumentos de gestão ambiental.

\section{Abstract}

The urban landscape is the synthesis of the urbanization process and, above all, of the relationship man and nature and of all sort of interventions in the natural environment and in the built environment. The green areas are essential elements of this urban landscape and components of heritage, built or natural. They have this importance not only for the notorious contribution in the physical aspect that marks the city's morphology, but also for what they represent to the life quality. The city of Recife, characterized by the immense water basin, associated to the green areas system, reveals itself as an environmental unit between water and vegetation cover, which makes it

1 Mes.; Gestão Ambiental; Instituto Federal de Educação, Ciência e Tecnologia, IFPE, Brasil; Professor da Faculdade de Ciências Humanas no curso de Arquitetura e Urbanismo e analista de desenvolvimento urbano da Prefeitura Municipal de Recife; Endereço: Prefeitura Municipal de Recife, Secretaria de Meio Ambiente e Sustentabilidade. Rua Fernando César, 65, Encruzilhada. CEP: 52041170 - Recife, PE - Brasil; E-mail: ubirajarapaz@hotmail.com

Autor para correspondências

\begin{tabular}{llllll}
\hline Ambiência & Guarapuava (PR) & v.I5 n.I & p. $222-239$ & Jan/Abr 20I9 & ISSN I808 - 025I
\end{tabular}


emblematic and unique. This study aims to analyze the Protected Units System of Recife, in what it establishes on the public green areas. In this study it was used the compilation of the devices established in the Master Plan of Recife that originated its institution, the grouping of its guidelines and components and its classification according to the typologies of the green areas that compose it. As a result, it was observed that with the institution of the System, in addition to an important planning instrument, it has been verified that it expanded and diversified the categories of areas.

Key words: Public Spaces; Protection Units of Nature; Environmental Management Tools.

\section{Introdução}

O processo de industrialização por que passaram as cidades, a partir do século XIX, resulta em grandes transformações. Se por um lado, havia um crescimento urbano vertiginoso, por outro, a infraestrutura, as condições de habitação e de circulação não o acompanharam. Com esse processo, vieram muitos problemas e, consequentemente, profundas transformações no ambiente; o que já era pouco e ruim, em termos de infraestrutura, tornara-se mais obsoleto e precário. Vieram as transformações da paisagem natural que deram lugar àquela sob a intervenção do homem. A paisagem urbana é, portanto, resultado dessas transformações. Ela é a síntese da (in) evolução do processo de urbanização e, sobretudo, da relação do homem com a natureza e de todos os formatos de intervenções no ambiente natural e no próprio ambiente construído.

O Brasil tem, hoje, conforme o IBGE no Censo de 2010, aproximadamente 80\% de sua população vivendo nas cidades, cujos processos de urbanização resultaram em cidades segregadas e fragmentadas do ponto de vista socioespacial, além de pressionarem suas expansões urbanas sobre áreas protegidas ou em áreas suscetíveis à inundação e de instabilidade geológica. Tudo isso, somado à falta de infraestrutura, sobretudo em áreas pobres, faz com que se acentue a disparidade entre áreas ricas e pobres, configurando a triste realidade urbana. A pauta das áreas verdes é condicionante preponderante para a caracterização das cidades, pois são elementos imprescindíveis na paisagem urbana e componentes do patrimônio, construído ou natural. Têm essa importância não só pela notória contribuição no aspecto físico que marca a morfologia da cidade, mas por serem, também, elementos influenciadores nos aspectos socioeconômicos, o que faz entender os diversos níveis de apropriação pela sociedade, dessas áreas.

Recife caracteriza-se, pelos seus significativos cursos d'água como o Rio Capibaribe, o Rio Beberibe e o Rio Tejipió, além de noventa e quatro canais que compõem sua macrodrenagem e pelos seus maciços vegetais, o que a torna uma cidade bastante peculiar e, ao mesmo tempo, com fisionomia complexa. Sá Carneiro (2010, p. 63), fazendo referência a Castro (1968), compara o território do Recife com um grande parque, ao caracterizá-lo, ora por inúmeros elementos naturais, ora por construções, “[...] Recife, com sua vegetação de mangue espalhada pelo território, a água dos rios entrando nos quintais das casas e os mocambos penetrando os mangues e rios, caracteriza-se por ser um espaço urbano desordenado". Recife, do ponto de vista da sua ocupação, é heterogêneo com seus assentamentos diversos (pobres e ricos), próximos territorialmente, mas distantes no que diz respeito ao direito à cidade. Por outro lado, dada a essa imensa rede de água associada ao sistema de áreas verdes, revela-se como unidade ambiental entre águas e cobertura vegetal. Essa configuração originou o Zoneamento da Cidade, materializando a percepção de que 
a gestão urbana e ambiental do Recife assumisse sua importante peculiaridade territorial, o que resultou na divisão do seu território, em duas Macrozonas - a Macrozona de Ambiente Natural e a Macrozona de Ambiente Construído - onde foram produzidas as suas correspondentes diretrizes, além de parâmetros para suas ocupações. Isso elucida a importância do verde no contexto do espaço urbano da cidade, não só pelos fatores expostos acima, mas também pelos valores históricos e culturais que configuram o processo de formação da cidade. Sá Carneiro (2010), ao comentar sobre o surgimento dos primeiros parques no Brasil, faz referência ao Recife, que teve implantado, em 1879, um dos primeiros passeios públicos, espaço reservado ao encontro da nobreza. A autora destaca ainda, as intervenções que fizera Maurício de Nassau, quando da sua passagem pelo Recife construiu, na ilha de Antônio Vaz, hoje Bairro de Santo Antônio, o Parque de Friburgo.

O Recife possui uma vasta legislação que dispõe sobre importantes instrumentos para a gestão das áreas verdes. Além do Plano Diretor, o Sistema Municipal de Unidades Protegidas (SMUP), os regulamentos que tratam dos Setores de Sustentabilidade Ambiental (SSA), os Projetos de Revitalização e/ou Implantação de Áreas Verdes (PRAV), exemplos desses principais regulamentos. Sendo assim, objetiva-se, neste trabalho, analisar o Sistema Municipal de Unidades Protegidas na instrumentalização da gestão das áreas verdes públicas do Recife.

Em meio à diversidade de abordagens sobre áreas verdes, percebem-se diferenças de concepções acerca desta categoria. Termos como "áreas verdes”, "espaços livres”, "área de lazer” são frequentemente utilizados como sinônimos quando, na verdade, não o são. Ainda que se utilize com mais frequência a denominação "áreas verdes", esbarra-se na falta de consenso o que gera equívocos, uma vez que, ao comparar "índices de áreas verdes”, de forma desarticulado do significado dos respectivos termos, sem rebatimento do seu mapeamento e da escala ou da metodologia utilizada na coleta de dados, faz com que os parâmetros de comparação sejam frágeis e pouco convincentes (NUCCI, 2008), ou como afirma Lima et al (1994):

As diferentes conceituações nas definições dos termos "área verde”, "área livre”, "espaço livre", "arborização urbana", "área de lazer", entre outros, tem-se mostrado, no mínimo, preocupantes, quer no ensino ou na pesquisa, bem como no planejamento e gestão desses espaços, onde profissionais da área, constantemente, deparam-se com a necessidade de uma linguagem única, que expresse, sem dar margem a erros, suas deliberações (LIMA et al, 1994, p. 540).

Apresentam-se, aqui, alguns conceitos, elucidando algumas visões acerca de áreas verdes, todavia, vale ressaltar que as variações conceituais nem sempre giram em torno de um único elemento que compõe o termo, alguns dão ênfase à sua função, outros ao elemento vegetação, enquanto que outros enfatizam a permeabilidade do solo. (Geiser et al, 1975) ${ }^{1}$ apud (Cavalheiro; Del Picchia, 1992), por exemplo, comenta que as áreas verdes são espaços que são utilizados para a recreação e mantidos pelo poder público, elas compõem os equipamentos urbanos, entre outros, incluindo as margens de rios e lagos; (Sanchotene, 2004) ${ }^{2}$ apud (Toledo e Santos, 2008) comentam que essas áreas, além de terem a função de recreação da população, são destinadas à preservação e implantação de vegetação, estas, por sua vez, podem ser de ocorrência natural ou implantada. Morero et al (2007) dão destaque à predominância nessas áreas da vegetação arbórea, chamando

I GEISER, R.R. et al. Áreas verdes nas grandes cidades. In: XXVI CONGRESSO NACIONAL DE BOTÂNICA, 26. Rio de Janeiro. Anais. Rio de Janeiro, 1975. A obra traz exemplos de cidades, como São Paulo, cuja classificação do termo relaciona-se com o objetivo de manter as condições ambientais e paisagísticas".

2 SANCHOTENE, M. do C. C. Conceitos e composição do índice de áreas verdes. Boletim Informativo da Sociedade Brasileira de Arborização Urbana, Piracicaba, n.1, p. 4-9, 2004. A autora sugere que as áreas verdes são responsáveis por diversos benefícios à cidade como a amenização das temperaturas elevadas e manutenção umidade do solo, por exemplo. 
a atenção da sua distribuição para a população sem distinção do nível social, já a enfatização do porte da vegetação diferencia da visão de Hardt (1994) ${ }^{3}$ apud Hülsmeyer e Souza (2007) em que, embora estabeleçam que as áreas verdes são espaços livres e se apresentem, fundamentalmente, com características naturais, o que introduz o fator permeabilidade, não especificam o porte da vegetação. Já Cavalheiro e Del Picchia (1992) sugerem que as áreas verdes são sempre espaços livres e que, aliás, deveriam ser chamadas por esta terminologia, pelo fato de ser mais abrangente:

Em nossa opinião o termo espaço livre deveria ser preferido ao uso de área verde, por ser mais abrangente, incluindo, inclusive as águas superficiais. O termo espaço aberto, a nosso ver é um anglicismo, pois a palavra inglesa é "open space", e não "freespace", tendo sido, erroneamente, traduzido, em português ao pé da letra. Argumentamos, ainda que para existir espaço aberto em urbanismo, em português, deveríamos contar com o termo área aberta (que é bidimensional), para podermos dar-lhe a tridimensionalidade que seria, então, espaço aberto (CAVALHEIRO; DEL PICCHIA, 1992, p. 30-31)

Lima et al (1994), em nome da Sociedade Brasileira de Arborização Urbana (SBAU), elaboraram uma carta consulta endereçada às instituições - institutos; faculdades, prefeituras de municípios com mais de 100 mil habitantes; profissionais que trabalham com o tema; além da própria SBAU - objetivando a obtenção de opiniões acerca do entendimento e aplicação dos termos: área verde, área livre, área de lazer, arborização urbana, espaços abertos, espaços livres e parques urbanos. Apesar dessa consulta ter sido solicitada, restritamente, à Região Sudeste e que o número de respostas foi pouco mais de $10 \%$ do universo consultado - 192 consultas - servira para que os autores fizessem uma compilação das respostas o que, de certa forma, apresentassem um panorama do entendimento sobre os termos (Figura 1).

\section{Figura 1 - Conceituação de termos relacionados com áreas verdes}

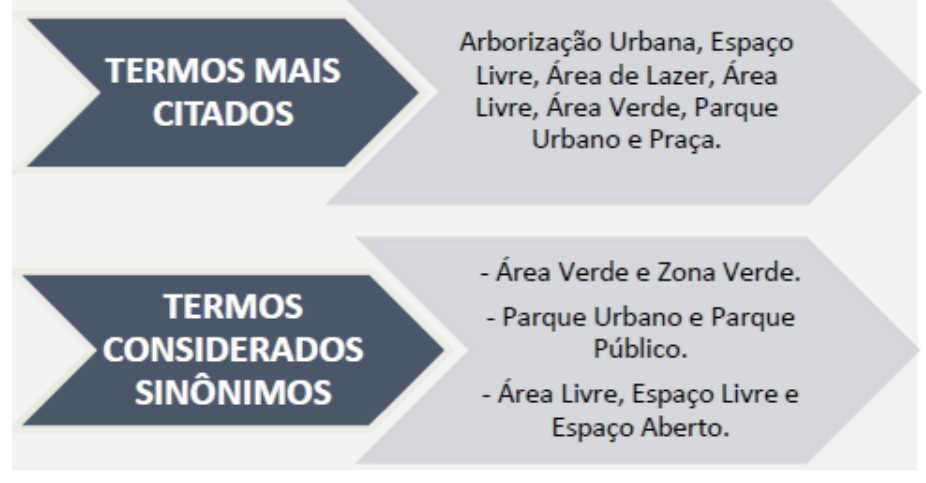

Fonte: Lima et al (1994).

A consulta comprova o múltiplo entendimento sobre o tema, sugerindo ser necessário o cuidado em suas utilizações e a necessidade de discussões serem feitas no sentido de agregar o máximo possível na perspectiva de uma convergência, observa-se que o termo espaço livre abrange os demais (LIMA et al, 1994), no mesmo sentido em que propuseram Sá Carneiro e Mesquita (2000) em suas classificação dos espaços livres do Recife, Lima et al (1994, p. 548) propõe que

3 HARDT, L. P. A. Subsídios ao planejamento de Sistemas de Áreas Verdes baseado em princípios de ecologia urbana: aplicação à Curitiba - PR. Curso de Pós-Graduação em Engenharia Florestal, Universidade Federal do Paraná. Dissertação de Mestrado, 1994. A dissertação traz como conceito de áreas verdes urbanas aquelas com características predominantemente naturais, independentemente do porte da vegetação. 
os espaços livres "têm que ser integrados ao uso do espaço, sua escala e função, devendo, esta última, satisfazer três objetivos principais: ecológicos, estético e de lazer”, eles se apresentam tal como mostra a Figura 2:

\section{Figura 2 - Classificação de espaços livres}

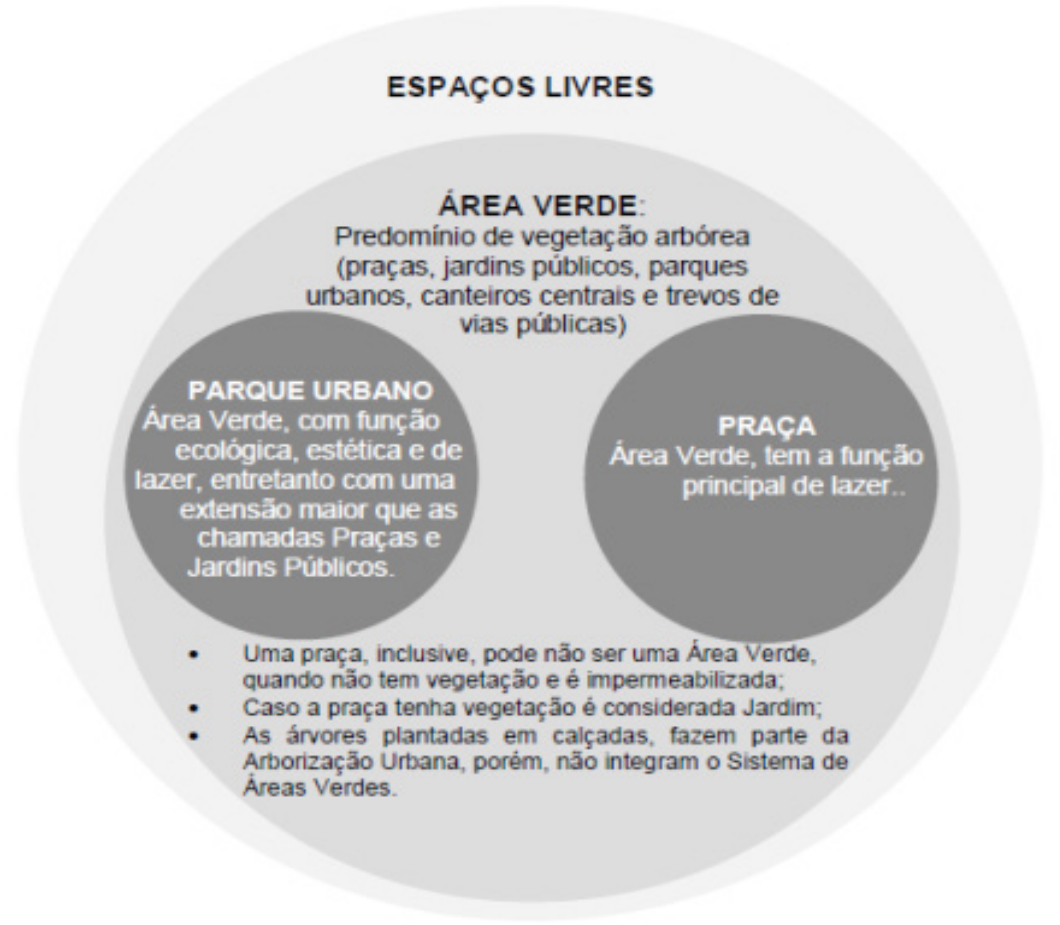

Fonte: Adaptado de Lima, et al (1994).

Outra questão importante diz respeito aos critérios para sua categorização. É difícil a comparação entre índices para diferentes localidades e, da mesma forma que há dissensos em suas definições, há diversidade de metodologias para sua seleção e mapeamento. Há mapeamentos que são feitos sem o critério de classificação ou categorização, enquanto outros os utilizam (BARGOS; MATIAS, 2011). (CAVALHEIRO et al 1999) 4 apud (FILHO; NUCCI, 2006), por exemplo, sugerem uma classificação, na tentativa de padronizar os conceitos, a partir de um roteiro que leva em consideração o zoneamento da cidade (zona urbana, zona de expansão urbana e zona rural), salientando que a zona urbana é constituída por sistemas de espaços - sistemas de espaços com construção; sistema de espaços livres de construção e pelo sistema de espaços de integração. Lembrando que as áreas verdes são um tipo especial de espaços livres, cuja característica principal, que as diferencia, é a vegetação que deve cumprir três objetivos - o ecológico ambiental, o estético e o lazer - além de responder alguns requisitos como percentual mínimo de solo permeável e de cobertura vegetal (70\%), além de servir a população e de propiciar as condições para recreação, tal como mostra a (Figura 3).

4 CAVALHEIRO et al, 1999. Proposição de Terminologia para o Verde Urbano. Boletim Informativo da Sociedade Brasileira de Arborização Urbana. Rio de Janeiro - RJ. Ano VII, n. 3, Jul/Ago/Set. 1999. 


\section{Figura 3 - Classificação de áreas verdes}

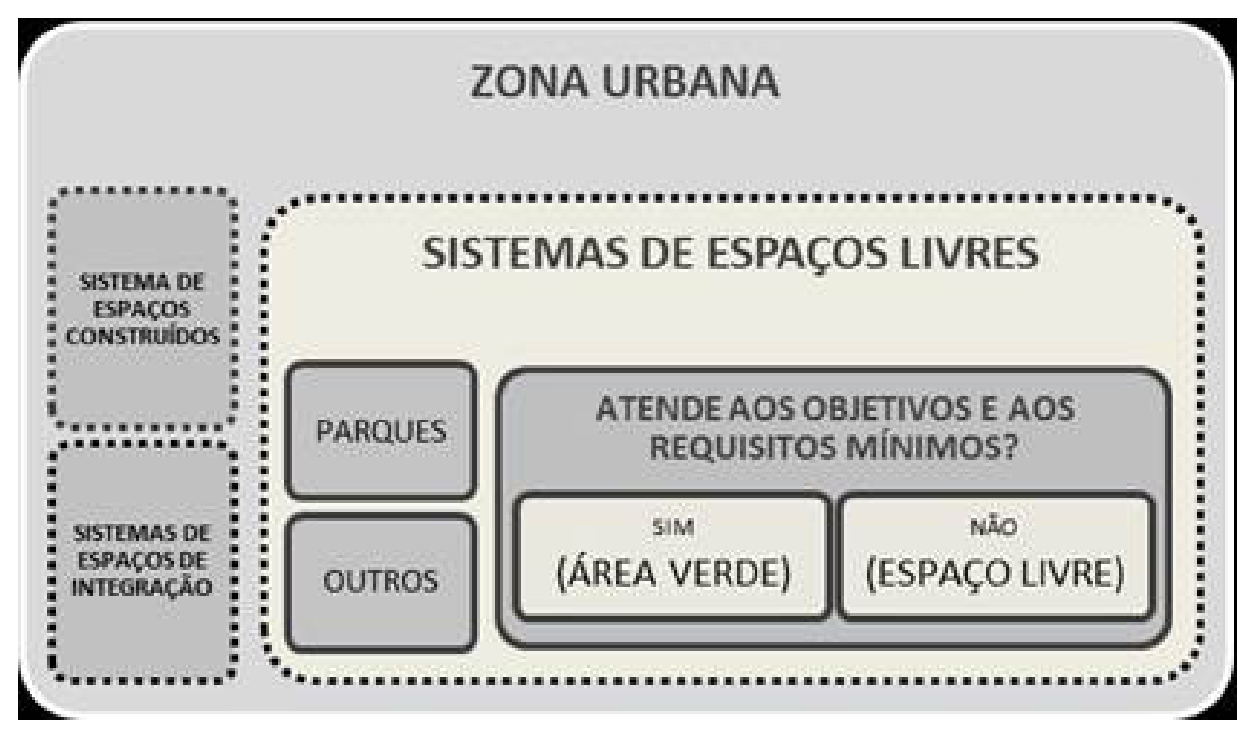

Fonte: Adaptado de Filho e Nucci (2006).

Já, Rosset (2005) propõe uma classificação de áreas verdes a partir de um modelo que ela denomina de Modelo de Classificação de Áreas Verdes Públicas (MCAVP), cujo procedimento consiste na utilização de uma chave de múltiplas escolhas, o resultado é a definição de classes a partir de elementos estruturais, funcionais e utilitários das áreas. Esse modelo, Oliveira $(1996)^{5}$ apud Bargos e Matias (2011) chama a atenção para o fato de que, apesar de permitir a definição de dezenas de classes distintas, faz-se necessário reconhecer que a classificação é um processo analítico e, consequentemente, o grande número de classes geradas a partir desse modelo, se constitui numa barreira para o estudo por ele proposto, dado que ele propôs a formação de "grupos", onde cada um dos oito grupos forma um determinado número de classes que resguardam características comuns. Nessa proposta, ele conclui que a definição de grupos de classes de áreas públicas não é um processo analítico, mas de síntese.

Condição imprescindível para o planejamento e a gestão das áreas verdes é o conhecimento da localização, além da sua classificação. Bargos (2010, p. 36) salienta que “[...] o conhecimento da localização e a classificação das áreas verdes no espaço urbano são de fundamental importância para que os responsáveis pelo poder público possam direcionar suas ações no controle, à manutenção e à ampliação dessas áreas”.

Vários estudos que tem como variável "localização", caso daqueles relacionados com o planejamento de áreas verdes, requerem a necessidade de análise do seu entorno ou da sua abrangência. Bargos (2010, p. 36) comenta que é cada vez maior “a preocupação com o raio de influência que estas áreas podem exercer em seu entorno". Esse raio de influência das áreas verdes, conforme define Oliveira (1996) apud Bargos (2010, p. 36), corresponde a "uma medida da distância máxima hipotética que se espere que uma pessoa caminhe para atingi-la, a partir de sua residência e pode ser determinado diretamente em termo de distância, ou estimado indiretamente baseado no tempo de percurso entre as residências e as áreas verdes". A autora chama a atenção para o fato de que esse raio de influência é definido única e exclusivamente para uma só área, o 5 OLIVEIRA, C.H. Planejamento ambiental na cidade de São Carlos (SP) com ênfase nas áreas públicas e áreas verdes: diagnóstico e propostas. Dissertação (Mestrado em Ecologia e Recursos Naturais) - Universidade Federal de São Carlos, São Carlos, SP, 1996. O autor propõe um modelo de classificação de áreas verdes públicas como ferramenta para o planejamento ambiental para a cidade de São Carlos-SP. 
que faz com que essa metodologia seja vulnerável, uma vez que aquele cidadão que resida dentro da área de influência possa escolher outra área para fora da mesma.

\section{Material e Métodos}

A área de estudo corresponde à cidade do Recife (Figura 4), capital do estado de Pernambuco e núcleo da Região Metropolitana do Recife, composta por 15 municípios. A cidade é a nona capital mais populosa (1.637.834 habitantes), mas é a vigésima terceira em área $\left(218,435 \mathrm{Km}^{2}\right)$ entre as capitais brasileiras, conforme estimativas do Instituto Brasileiro de Geografia e Estatística (IBGE, 2018), o que lhe dá uma alta densidade demográfica, a quarta maior do Brasil, com 7 039,64 habitantes por quilômetros quadrados atrás apenas de Fortaleza, São Paulo, e Belo Horizonte.

\section{Figura 4 - Localização da Cidade do Recife, Pernambuco, Brasil.}

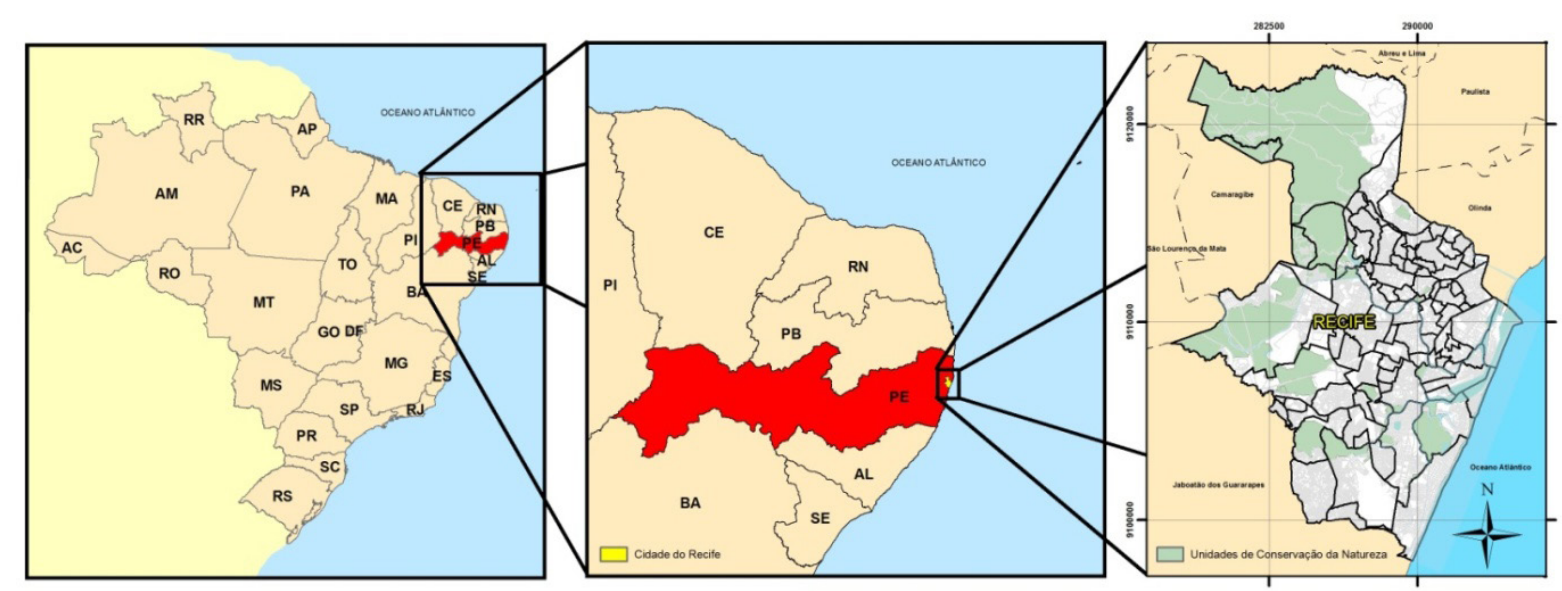

Fonte: Recife (2016)

Recife está dividido em seis Regiões Político-Administrativas (RPA1, RPA2, RPA3, RPA4, RPA5 e RPA6), cada uma composta por três microrregiões instituídas pela Lei Municipal 16.293/1997, cujo objetivo é o de formular, executar e avaliar as políticas e o planejamento governamentais. Cada Região Político-Administrativa, com suas respectivas microrregiões, é composta por 94 Bairros estabelecidos pelo Decreto Municipal 14.452, de 26 de outubro de 1988.

O procedimento metodológico para a análise do SMUP, objeto deste estudo, seguiu, basicamente, duas etapas:

Descrição do SMUP, levantando os aspectos que motivaram sua origem e fundamentação e, a partir da Lei 18014/2014, agrupando seu conteúdo quanto às suas diretrizes e componentes. Destaque à classificação das unidades de proteção, considerando suas tipologias e características, localização e quanto às suas ocorrências no território recifense.

Estas etapas foram precedidas de uma perscrutação a literatura sobre áreas verdes que fundamentaram a linha conceitual exposta no presente trabalho. 


\section{Resultados e Discussão}

O Plano Diretor do Recife, Lei Municipal n 17.511/2008, em seu capítulo que trata da Política Ambiental Urbana, estabelece a garantia da manutenção das áreas permeáveis no território do Município, uma importante referência sobre a importância da permeabilidade do solo, subentendendo-se a necessidade de implantação ou manutenção de áreas verdes da cidade.

O Plano Diretor revela a estrutura espacial como sendo imprescindível na caracterização da divisão territorial do Recife. O Artigo 84 daquela lei, define a estrutura espacial do Recife pela configuração dos seus ambientes naturais e pelas edificações nos quais acontecem os diversos usos e funções, além da infraestrutura instalada e dos equipamentos públicos (RECIFE, 2008). Já o Artigo 85, estabelece que nessa estruturação espacial deverão ser levados em consideração, entre outros fatores "[...] a rede hídrica da cidade; [...] os maciços vegetais, como forma de assegurar o patrimônio natural existente, promovendo o equilíbrio do ecossistema urbano [...]” (RECIFE, 2008) (supressões nossas). É uma clara evidência da importante estratégia tomada na formulação da Política Ambiental Urbana do Recife ao colocar o verde urbano como elemento fundamental na promoção do equilíbrio ambiental (Figura 5).

A divisão territorial, estabelecida pelo Plano, consiste na definição do Zoneamento que é um importante instrumento de gestão do solo urbano, cuja função é a divisão do território municipal, e sobre o qual recaem diretrizes e parâmetros de ordenamento. Ao dividir o território do Recife em duas grandes áreas, fruto da compreensão de que ele é essencialmente formado pelas suas características explícitas, denominando-as em Macrozonas de Ambientes Naturais (MAN) e Macrozonas de Ambientes Construídos (MAC) (Figura 6), não se trata de separálas e, nem de perto, compreendê-las isoladamente, mas da aplicação de uma metodologia cujo princípio essencial baseia-se na necessidade, mesmo que suas formações predominantes sejam diferentes, da interface entre essas partes e da importância que uma se põe sobre a outra. Sobre as Zonas de Ambiente Natural - ZAN recaem os pressupostos da compatibilização dos padrões de ocupação com a preservação dos elementos naturais da paisagem urbana, na perspectiva de garantir a preservação dos ecossistemas, revelando novamente a forte intenção de proteção e ampliação do verde urbano na cidade. 


\section{Figura 5 - Maciços vegetais e Figura 6-Plano Diretor do Recife bacias hidrográficas/ Fundamentação da I Divisão Territorial divisão territorial do Recife}

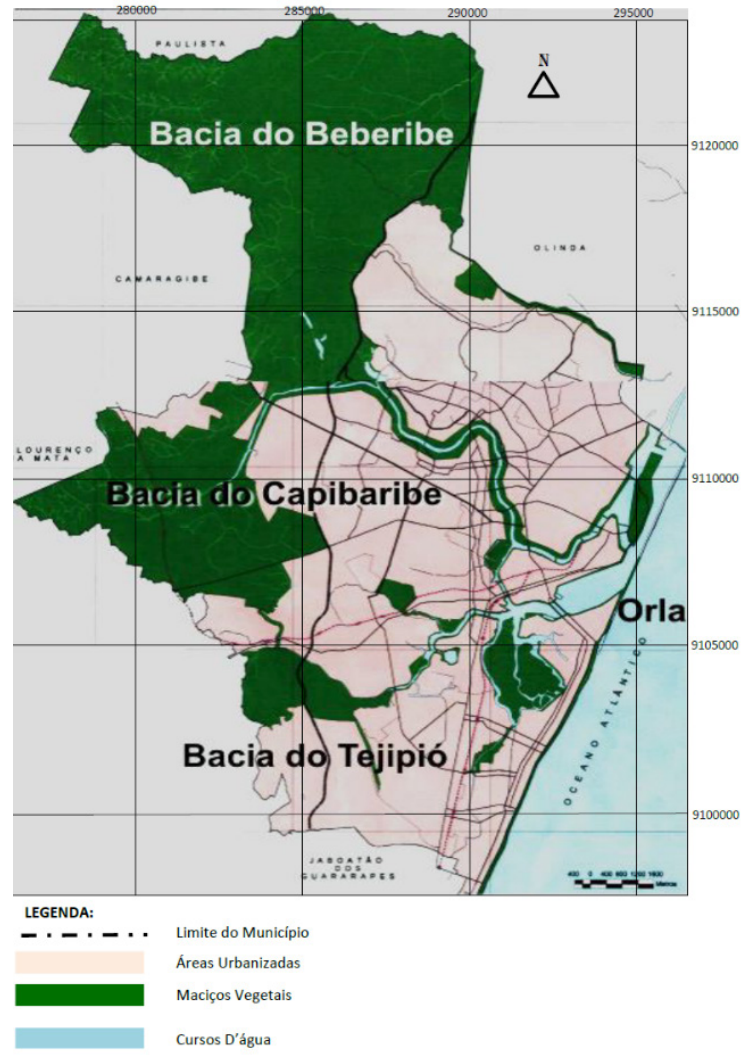

Fonte: Recife (2004)

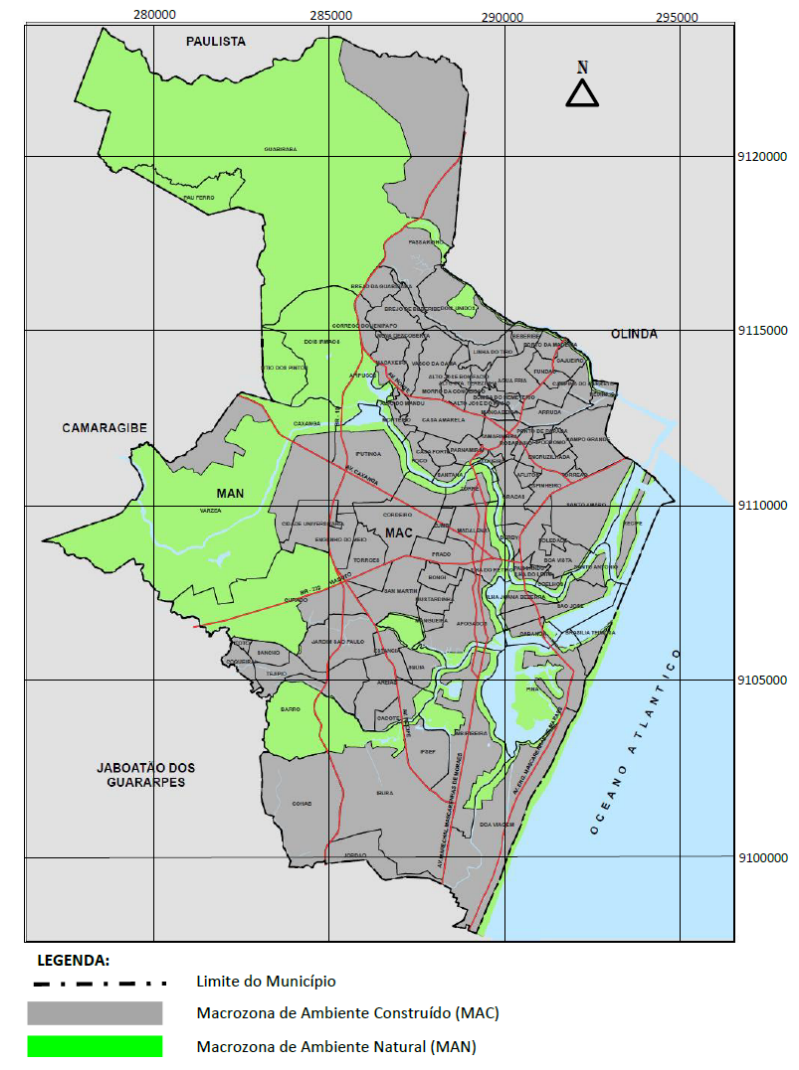

Fonte: Recife (2008)

Percebe-se, no Plano Diretor, a intensão de integrar a gestão das áreas verdes com o uso do solo urbano. Sob o seu manto, de forma clara e contundente, as áreas verdes adquiriram significativas formas de proteção a partir, entre outras questões, de restrições no processo de ocupação, inclusive, nas faixas limítrofes dessas áreas. Exemplo disto é a instituição dos Setores de Sustentabilidade Ambiental - o SSA 1 e o SSA 2 (Figuras 7 e 8). No caso do SSA 1, inicialmente definido pela Lei Municipal 16.930/2003, apenas como SSA, tem a finalidade de "promover a revitalização e o incremento do patrimônio ambiental da cidade” (RECIFE, 2003). 


\section{Figura 7 - Setor de Sustentabilidade Ambiental SSA1}

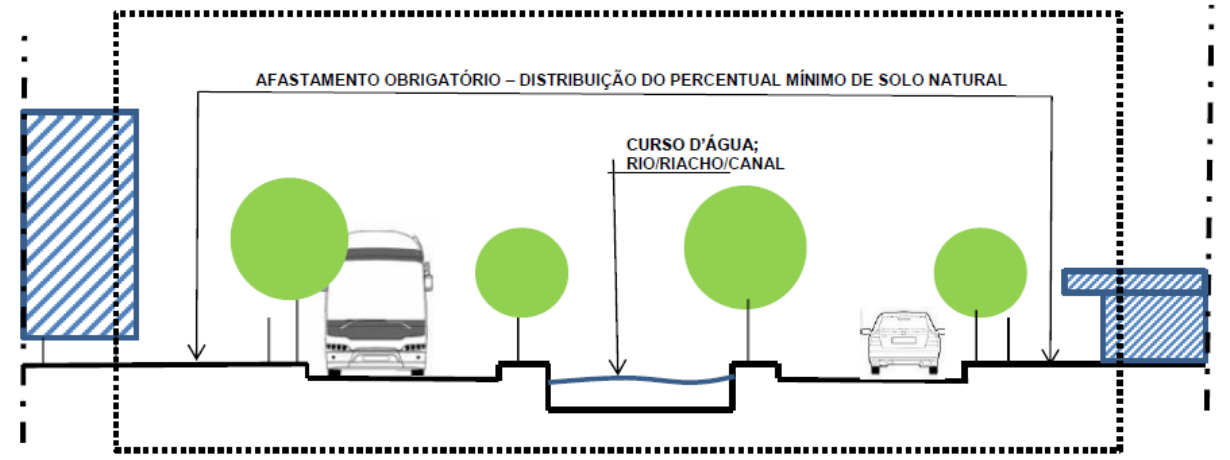

Fonte: Adaptado de Recife (2016).

Figura 8 - Setor de Sustentabilidade Ambiental 2 (SSA 2)

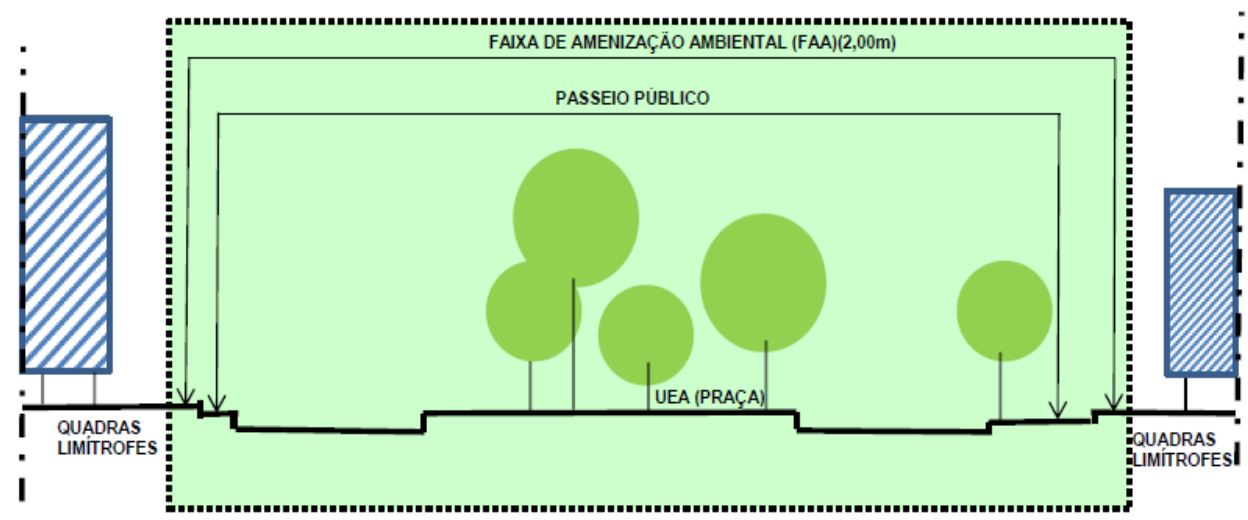

Fonte: Adaptado de Recife (2015).

O Sistema Municipal de Unidades Protegidas (SMUP), previsto no Plano Diretor do Recife, foi instituído pela Lei Municipal 18.014/2014 e está fundamentado naquele mesmo plano, além do Código Municipal do Meio Ambiente e das legislações federal (Lei 9.985/2000 que institui o Sistema Nacional de Unidades de Conservação da Natureza) e estadual (Lei 13.787/2009 que define o Sistema Estadual de Unidades de Conservação da Natureza) referentes às unidades de conservação no âmbito das duas esferas. A Lei define o SMUP como sendo "um sistema que agrega os atributos naturais da cidade, abrangendo toda a diversidade de ecossistemas existentes no território municipal, [...] visando à melhoria da qualidade de vida humana”. Tratase do conjunto de áreas formado pelos maciços vegetais localizados em toda parte do território municipal fazendo parte, inclusive, os espaços que conectam essas áreas, como os cursos e corpos d'água.

O SMUP é um importante instrumento para a gestão das áreas verdes públicas do Recife, como bem define a Lei 18.014/2014 que especifica a promoção da criação, implantação 
e conservação dessas áreas através das suas zonas urbanísticas e regiões político-administrativas, o que é uma estratégia originária no Plano Diretor que foi regulamentado por essa Lei. Já, em seu preâmbulo a Lei traz algumas definições importantes institucionalizando, como "área verde" - "toda área de domínio público ou privado, onde predomina qualquer forma de vegetação, nativa ou exótica, distribuída em seus diferentes estratos: arbóreo, arbustivo e herbáceo”. Portanto, o SMUP é o principal instrumento de gestão e de planejamento das áreas verdes do Recife que estabelece diretrizes de conservação do verde urbano na perspectiva da sustentabilidade urbana (Tabela 1).

\section{Tabela 1- Diretrizes do Sistema Municipal de Unidades Protegidas do Recife}

\begin{tabular}{|c|}
\hline 1. Reconhecimento das singularidades das paisagens do Recife. \\
\hline $\begin{array}{c}\text { 2. Integração dos ecossistemas remanescentes do sítio natural com as Unidades de Equilíbrio } \\
\text { Ambiental. }\end{array}$ \\
\hline $\begin{array}{c}\text { 3. Proteção das áreas naturais, possibilitando a integração paisagística entre os maciços vegetais e os } \\
\text { espaços vegetados. }\end{array}$ \\
\hline 4. Alocação adequada de recursos financeiros necessários à gestão e conservação integradas. \\
\hline 5. Sustentabilidade econômica. \\
\hline 6. Incentivo à administração das Unidades Protegidas pela Sociedade Civil Organizada. \\
\hline $\begin{array}{c}\text { 7. Participação popular e controle social, bem como a transparência e disponibilização das informações, } \\
\text { proposições e estudos para a coletividade. }\end{array}$ \\
\hline
\end{tabular}

Fonte: Adaptado de Recife (2014)

As unidades protegidas no SMUP, espelhadas nos sistemas nacional (SNUC) e do estado de Pernambuco (SEUC), são definidas a partir de categorias, em função dos seus característicos atributos e da sua significativa importância ambiental e paisagística. As Unidades Protegidas (UP) do Recife estão constituídas nas categorias: Jardins Botânicos - JB; Unidades de Conservação da Natureza - UCN; Unidades de Conservação da Paisagem - UCP e Unidades de Equilíbrio Ambiental - UEA (Figura 9). 


\section{Figura 9- Sistema Municipal de Unidades Protegidas}

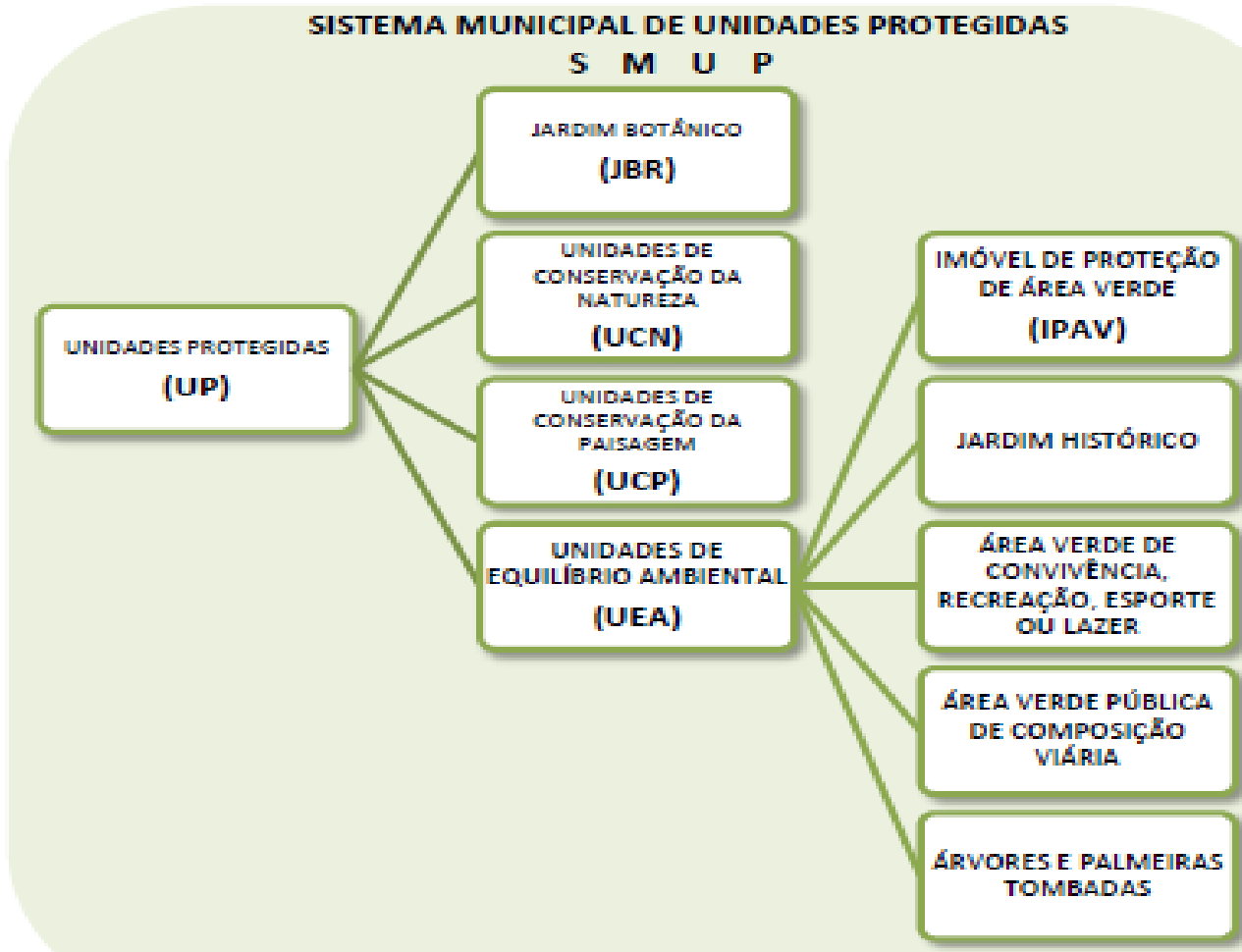

Fonte: Adaptado de Recife (2015).

O Jardim Botânico, uma das categorias instituída pelo SMUP, é caracterizada como uma unidade protegida que possui em toda sua superfície, ou em parte dela, coleções de plantas vivas, cientificamente reconhecidas, organizadas, documentadas e identificadas visando estudos, pesquisas e documentação do patrimônio florístico existente (Figura 10). A coleção, total ou parcial, deverá estar acessível às pessoas, servindo como suporte à educação, às pesquisas científicas, à cultura, ao lazer e à conservação ambiental (RECIFE, 2016). O Plano Diretor do Jardim Botânico e normas específicas versarão sobre quaisquer alterações, atividades ou modalidades de utilização em seu interior.

Figura 10 - Jardim Botânico do Recife, uma das trilhas existentes

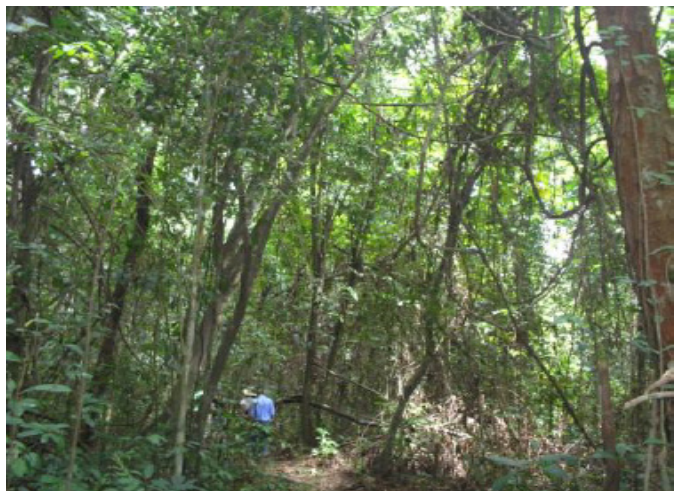

Fonte: Recife, 2014 
O jardim Botânico do Recife (JBR), única área desta categoria na cidade, criado pelo Decreto Municipal no 11.341/1979, possui área aproximada de 10,7 hectares, adjacente à Unidade de Conservação do Curado, de domínio público e bastante visitado pela população. Estabelecidos alguns requisitos, poder-se-ão ser criados outros jardins botânicos.

As Unidades de Conservação da Natureza correspondem aos espaços territoriais, cujas características naturais são relevantes para a conservação. A cidade do Recife, possui vinte e cinco unidades de conservação com variadas características, entre as quais, cinco são da categoria Área de Proteção Ambiental (APA) (Figura 11). As UCN, para suas criações e gestão, observam as normas e categorização definidas na Lei Federal 9.985/2000, a lei que instituiu o Sistema Nacional de Unidades de Conservação da Natureza (SNUC).

\section{Figura 11 - APA das Capivaras}

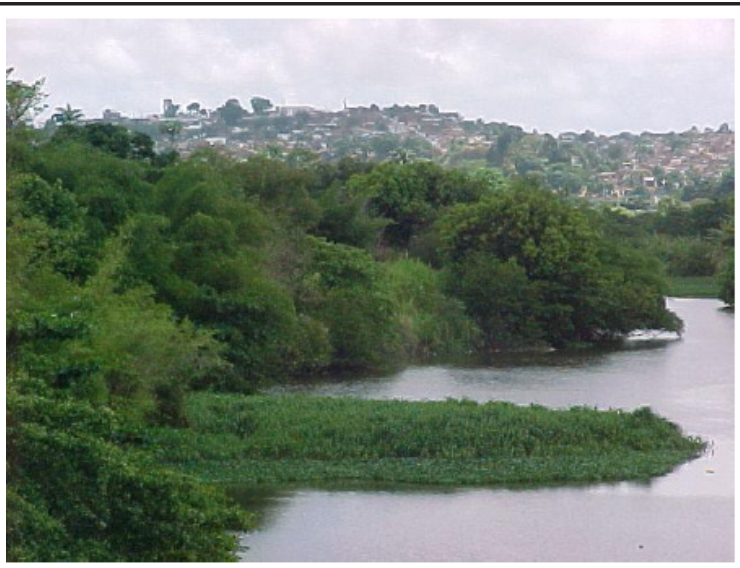

Fonte: Recife, 2014

A Unidade de Conservação da Paisagem (UCP), conforme se verifica na Figura 12, é a unidade protegida correspondente ao recorte territorial representado por elementos que congregam a relação entre o sítio natural e os valores materiais e imateriais, consolidados ao longo do tempo e expressos na identidade da cidade do Recife. Conforme a Lei do SMUP, para que se possa considerar como UCP, a área deve estar munida de pelo menos três características:

"I - área de ocupação humana com significativos atributos naturais e culturais, que compreende sítios de valor paisagístico, os quais materializam momentos históricos da ocupação da cidade, de interesse natural e cultural; II - área que abriga exemplares da biota local ou regional, cujos atributos naturais justifiquem sua proteção e conservação, em face de sua relevância ecológica; III - área que constitui um recorte de paisagem caracterizado por uma identidade peculiar do Recife, que relaciona o suporte físico-geográfico às intervenções antrópicas, apropriadas pelos recifenses como símbolo e memória da cidade "(RECIFE, 2014). 


\section{Figura 12 - UCP/Parque da Jaqueira - Alameda Central}

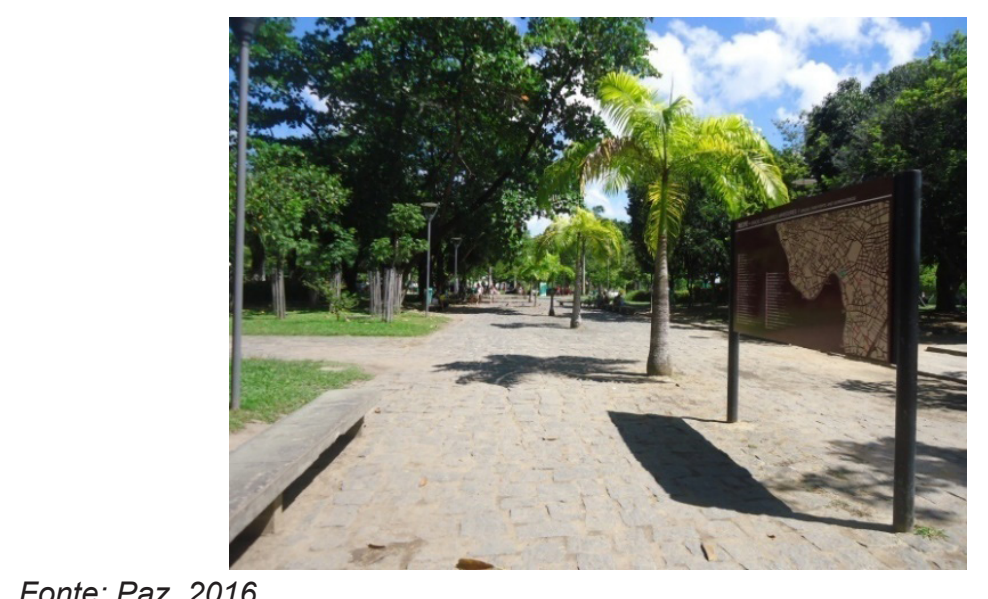

Fonte: Paz, 2016

As Unidades de Equilíbrio Ambiental (UEA) são unidades protegidas dentro da malha urbana do município, em sua maioria, munidas de vegetação. A maioria das UEA são parques e praças (Figuras 13 e 14), além dos Imóveis de Proteção de Área Verde (IPAV); de Áreas Verdes Públicas de Composição Viária; e das Árvores e Palmeiras Tombadas, fundamentais para a amenização climática e pela conservação da paisagem urbana. No caso do Jardim Histórico, cuja "composição arquitetônica e vegetal que, do ponto de vista da história ou da arte, apresenta um interesse público, sendo, como tal, considerado um monumento" (RECIFE, 2014), UEA criada a partir da preservação dos Jardins de Burle Marx é, também, área de convivência, recreação, esporte e lazer. As UEA estão divididas nas seguintes subcategorias:

Imóvel de Proteção de Área Verde (IPAV) - corresponde aos imóveis de propriedade particular ou não de acesso restrito constituído de "área verde contínua e significativa para a amenização do clima e qualidade paisagística da cidade” (RECIFE, 2004).

O Jardim Histórico-Foram criados 15 jardins históricos, denominados "Jardins de Burle Marx" em homenagem ao paisagista Roberto Burle Marx que deixou um legado em matéria de projeto e implantação de espaços públicos (jardins, praças e parques) na cidade do Recife.

A Área Verde de Convivência, Recreação, Esporte ou Lazer - são aquelas áreas que têm "função ecológica, paisagística ou recreativa, que propicia a melhoria da qualidade estética, funcional e ambiental da cidade" (RECIFE, 2014).

A Área Verde Pública de Composição Viária - são espaços públicos integrantes do sistema viário urbano, conforme a Lei 18.014/2014, e correspondem aos “canteiros centrais de vias urbanas, rotatórias, áreas remanescentes de abertura de vias e refúgios viários”.

As Árvores e Palmeiras Tombadas - nestes casos, correspondem aos exemplares de vegetação de significativa importância, prevista na Lei 18.014, seja pela sua raridade, localização, condição de porta semente ou expressão histórica e que, portanto, devem ser preservadas e devem ter seu manejo de acordo com a Lei Municipal 15.072/1988 e suas alterações posteriores. 


\section{Figura 13 - UEA/ Praça de Casa Figura 14 - UEA/Praça do Forte no bairro do mesmo nome \\ Entroncamento no bairro das Graças}

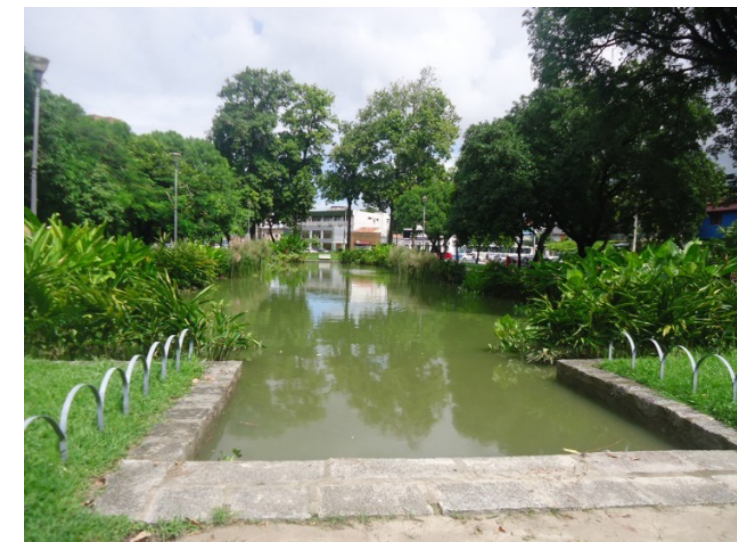

Fonte: Paz, 2016

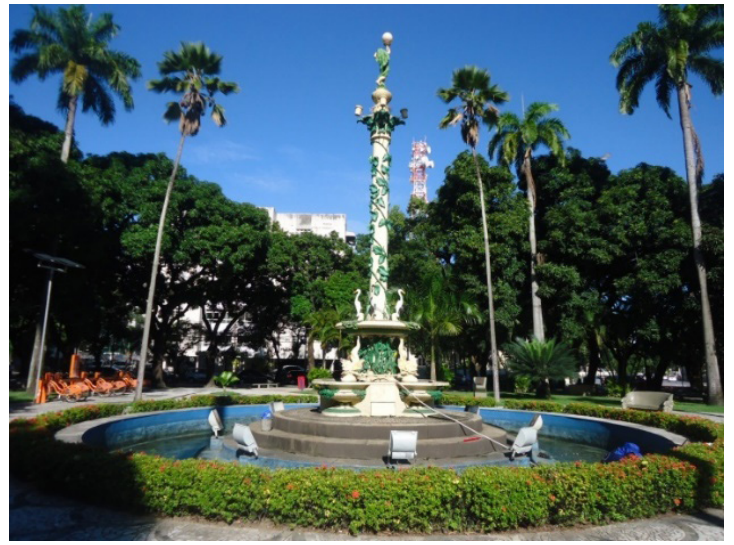

Fonte: Paz, 2016

Enfim, esse é o conjunto de áreas verdes do Recife, entre públicas e não públicas, que configura o território da cidade conforme mostra a Figura 15. Trata-se de um sistema de áreas verdes singular no que se refere a sua estruturação, unificando diversas tipologias - da unidade de conservação, perpassando pelo Jardim Botânico até as minúsculas unidades de equilíbrio ambiental como refúgios, canteiros e jardins.

\section{Figura 15 - Unidades Protegidas e Setores de Sustentabilidade Ambiental}

\begin{tabular}{|l|l|l|}
\hline & LEGENDA \\
\hline LMITE DO MUNICIPIO \\
\hline
\end{tabular}

Traças e Parques

Setores de Sustentabilidade Ambiental

Fonte Recife, 2008

Na configuração da cidade do Recife, segundo o SMUP, sob o aspecto da distribuição das áreas verdes em seu território, conforme demonstra a Tabela 2, verifica-se que as Unidades de Equilíbrio Ambiental (UEA), em termos de quantidade, é a categoria mais representada, embora não a seja em termos de superfície, ocupando o segundo lugar entre as categorias. As Unidades 
de Conservação da Natureza (UCN), em termos de superfície, são as que melhor representam as unidades protegidas no território recifense.

\section{Tabela 2 - Configuração das áreas verdes no Sistema Municipal de Unidades Protegidas do Recife}

\begin{tabular}{|c|c|c|c|c|c|c|c|}
\hline \multicolumn{8}{|c|}{ Unidades Protegidas do Recife } \\
\hline $\begin{array}{r}\text { Ur } \\
\text { Con } \\
\mathrm{I}\end{array}$ & $\begin{array}{l}\text { des de } \\
\text { jação da } \\
\text { Ireza } \\
\text { CN) }\end{array}$ & Jard & $\begin{array}{l}\text { otânico } \\
\text { 3) }\end{array}$ & $\begin{array}{r}\text { Ur } \\
\text { Con } \\
\mathrm{P}\end{array}$ & $\begin{array}{l}\text { les de } \\
\text { ação da } \\
\text { sem } \\
\text { P) }\end{array}$ & $\begin{array}{r}\mathrm{U}_{1} \\
\text { Equilíb }\end{array}$ & $\begin{array}{l}\text { des de } \\
\text { Ambiental } \\
\text { A) }\end{array}$ \\
\hline QDE. & $\begin{array}{c}\text { ÁREA } \\
\text { (ha) }\end{array}$ & QDE. & $\begin{array}{c}\text { ÁREA } \\
\text { (ha) }\end{array}$ & QDE. & $\begin{array}{c}\text { ÁREA } \\
\text { (ha) }\end{array}$ & QDE. & $\begin{array}{c}\text { ÁREA } \\
\text { (ha) }\end{array}$ \\
\hline 25 & $6.315,68$ & 1 & 10,7 & 2 & 12,83 & 1.034 & 298,70 \\
\hline
\end{tabular}

Fonte: Adaptado de Recife (2016)

A gestão do SMUP, tal como define a lei que o criou, é feita pela conjunção de três órgãos - pelo Conselho Municipal do Meio Ambiente (COMAM), responsável pela supervisão da implementação do SMUP, sobretudo no que se refere à proposição de implantação de unidades protegidas e pela fixação de normas; pelo órgão gestor de políticas ambientais, caso que, atualmente, cabe à Secretaria de Meio Ambiente e Sustentabilidade (SMAS) que faz a execução das políticas como licenciamento, fiscalização e coordenação do SMUP, além de administrar as unidades protegidas; e pelos órgãos de apoio (conselhos gestores) e pelos da administração da Prefeitura do Recife ou de outras instâncias governamentais.

\section{Considerações Finais}

Os resultados deste trabalho apontam, em um primeiro momento, para uma conclusão de que a cidade do Recife dispõe de um importante instrumento sobre as áreas verdes. Amplo no que diz respeito às diversas características das áreas, denominando-as de unidades protegidas, portanto, introduzindo a conservação tanto para aqueles grandes maciços vegetais, como para os pequenos fragmentos como as pequenas praças e canteiros centrais. Deste modo constata-se que, tanto as áreas verdes representadas pelas Unidades de Conservação da Natureza, localizados, em sua maioria, nas extremidades das áreas adensadas construtivamente, caso das UCN do Curado, de Dois Irmãos, de Beberibe, e das APA da Mata do Engenho Uchôa e da Mata da Várzea até a árvore e palmeira tombadas e às minúsculas áreas dentro do perímetro mais denso da cidade têm guarida no Sistema Municipal de Unidades Protegidas (SMUP).

A segunda impressão, não menos importante, revela-se no que diz respeito à fundamentação na qual baseou-se a formulação e consequente instituição do SMUP. Previsto na Lei Municipal 17.511/2008, o Plano Diretor do Recife, fora concebido já no reconhecimento de que o território do Recife é formado pelos ambientes construídos e naturais caracterizados por ambiências diversas e tendo como componentes fragmentos de verdes diluídos em todo sistema urbano. Esta fundamentação deu o tom para a divisão territorial do Recife que culminou com o seu Zoneamento, apresentando diretrizes para a diversas zonas inseridas tanto na Macrozona de Ambiente Natural, quanto na Macrozona de Ambiente Construído. 
Por último, constata-se a semelhança com os sistemas nos níveis federal e estadual no que diz respeito à estrutura de gestão. Tal como aquelas leis, o SMUP também é gerido por três órgãos - o órgão consultivo e deliberativo que cabe ao Conselho Municipal do Meio Ambiente; o órgão que coordena o SMUP, que é a Secretaria de Meio Ambiente e Sustentabilidade; e órgãos executores, exercidos por órgãos internos da administração direta e indireta da Prefeitura e de outras instâncias governamentais. Observam-se, na prática, algumas fragilidades quanto à gestão, o que vulnerabiliza o SMUP: a sistemática da gestão não tem ocorrido no que diz respeito à integração entre os órgãos que o compõem; o retardo da formulação dos planos de manejo; dificuldades na manutenção; e, por fim, deficiências no controle e na fiscalização.

Faz-se necessário, portanto, que a situação da gestão das áreas verdes, considerando o SMUP como um importante instrumento, seja considerada de forma mais sistemática e eficiente pela Prefeitura, utilizando de todos os mecanismos disponíveis e articulando a sociedade para a busca da sua efetivação plena.

\section{Referências}

BARGOS, D. C. Mapeamento e análise das áreas verdes urbanas como indicador da qualidade ambiental urbana: estudo de caso de Paulínia-SP. 2010.139 p. Dissertação (Mestrado em Geografia) Instituto de Geociências, Universidade Estadual de CampinasSP.

BARGOS, D. C.; MATIAS, L.F. Áreas verdes urbanas: um estudo de revisão e proposta conceitual. Revisbau, Piracicaba, SP. v.6, n.3, p.172-188, 2011.

BUCCHERI FILHO, A.T; NUCCI, J.C. Espaços Livres, Áreas Verdes e Cobertura Vegetal no Bairro Alto da XV, Curitiba - PR. Revista do Departamento de Geografia, v. 18 , p. $48-59,2006$

CAVALHERO,F.; DEL PICCHIA, P. C. D. Áreas verdes: conceitos, objetivos, diretrizes para o planejamento. In: CONGRESSO BRASILEIRO SOBRE ARBORIZAÇÃO URBANA E ENCONTRO SOBRE ARBORIZAÇÃO URBANA, 4. Vitória, 13 a 18 de setembro, 1992. Anais, Vitória, 1992. p.29-38.

HÜLSMEYER, A.F; SOUZA, R.C.A. Avaliação das áreas permeáveis como subsídio ao planejamento de áreas verdes urbanas de Umuarama- PR. Akrópolis, Umuarama- PR, v.15, n. 1 e 2, p $49-59$, jan/jun. 2007.

LIMA, A. M. L. P.; CAVALHEIRO, F.; NUCCI, J.C.; SOUSA, M.A.L.B.; FILHO, N. DEL PICCHIA, P.C.D. Problemas de utilização na conceituação de termos como espaços livres, áreas verdes e correlatos. In: CONGRESSO DE ARBORIZAÇÃO URBANA. 2, 1994, São Luís, MA Anais... São Luís: SBAU. p. 539-553. 1994 
MORERO, A.M.; SANTOS, R. F. DOS; FIDALGO, E. C. C. Planejamento ambiental de áreas verdes: Estudo de caso em Campinas-SP. Inst. Flor, São Paulo, v. 19, n. 1, p. 19-30, jun. 2007.

NUCCI, J. C. Qualidade ambiental e adensamento urbano: um estudo de ecologia e planejamento da paisagem aplicado ao distrito de Santa Cecília (MSP) / João Carlos Nucci. - Curitiba: O Autor, 2008.

PAZ, U. F. Gestão de áreas verdes públicas no Recife, Pernambuco, Brasil. 2016.197p. Dissertação (Mestrado em Gestão Ambiental) Instituto Federal de Educação, Ciência e Tecnologia de Pernambuco- PE.

RECIFE. Lei no 17.511, de 29 de dezembro de 2008. Promove a revisão do Plano Diretor do Município do Recife. Diário Oficial [do Município do Recife], Recife, PE, v. 1, n. 128, 30 dez. 2008. Seção I, p. 32-41.

RECIFE. Lei no 18.014, de 9 de maio de 2014. Institui o Sistema Municipal de Unidades Protegidas - SMUP Recife e dá outras providências. Diário Oficial [do Município do Recife], Recife, PE, v. 1, n. 245, 10 mai. 2014. Seção IV, p. 37-52.

SÁ CARNEIRO, A. R.; MESQUITA, L. DE B. Espaços Livres do Recife. Recife: Prefeitura da Cidade do Recife; UFPE, 2000.124p.

SÁ CARNEIRO, A. R. Parque e Paisagem: Um olhar sobre o Recife. Recife: Editora Universitária - UFPE, 2010.

TOLEDO, F.S.; SANTOS, D.G. Espaços Livres de Construção. Revista da Sociedade Brasileira de Arborização Urbana, Piracicaba - SP, v. 3, n. 1, p. 73-91, mar., 2008. 